\title{
A HIV stigma reduction intervention for people living with HIV and their families
}

\author{
Johanna Beatrix Pretorius ${ }^{1}$, Minrie Greeff*, Fazel Ebrihiam Freeks ${ }^{2}$, \\ Annamarie Kruger ${ }^{3}$ \\ Africa Unit for Transdisciplinary Health Research (AUTHOR), North-West University, Private Bag X6001, \\ Potchefstroom, 2520, South Africa
}

\section{A R T I C L E I N F O}

Article history:

Received 6 February 2015

Accepted 16 November 2015

Available online 12 April 2016

Keywords:

Close family member

Community-based

HIV

Intervention

Stigma

\begin{abstract}
A B S T R A C T
Background: The diagnosis of HIV is life-changing that requires people not only to deal with the disease but also to cope with the stigma attached to HIV. People living with HIV (PLWH) as well as their close family members (CFM) are stigmatised; however, CFM also stigmatise PLWH. This interaction affects the relationship between PLWH and their CFM.

Aim: To explore and describe the experiences of PLWH and CFM during and after a community-based HIV stigma reduction intervention in both an urban and rural setting in the North-West.

Method: A qualitative description approach through in-depth interviews was used in both settings. Purposive sampling was used for the PLWH and snowball sampling for the CFM. Data was analysed using open coding.

Results: Both urban and rural groups gained a richer understanding of HIV stigma and how to cope with it. The relationships were enriched by PLWH feeling more supported and CFM realising how they stigmatised PLWH and that they should be more supportive. Leadership was activated in PLWH and CFM through the stigma reduction project that they participated in.

Conclusion: No significant differences were found between rural and urban communities, thus the intervention can be implemented with similar results in both settings. The intervention showed positive outcomes for both PLWH and CFM. Bringing PLWH and CFM together during an intervention in an equalised relationship proved to be useful as PLWH felt more supported and CFM showed much more compassion towards PLWH after the intervention.
\end{abstract}

(C) 2015 The Authors. Publishing services by Elsevier B.V. on behalf of Johannesburg University. This is an open access article under the CC BY-NC-ND license (http:// creativecommons.org/licenses/by-nc-nd/4.0/).

\footnotetext{
* Corresponding author. Private Bag X6001, Potchefstroom, North-West Province, 2522, South Africa. Tel.: +27 (018) 2992092.

E-mail addresses: 10352880@nwu.ac.za (J.B. Pretorius), minrie.greeff@nwu.ac.za (M. Greeff), 10589686@nwu.ac.za (F.E. Freeks), 10062416@nwu.ac.za (A. Kruger).

${ }^{1}$ Tel.: +27 (018) 2994355 .

2 Tel.: +27 (018) 2994225 .

3 Tel.: +27 (018) 2992641.
}

Peer review under responsibility of Johannesburg University. http://dx.doi.org/10.1016/j.hsag.2015.11.005

1025-9848/@ 2015 The Authors. Publishing services by Elsevier B.V. on behalf of Johannesburg University. This is an open access article under the CC BY-NC-ND license (http://creativecommons.org/licenses/by-nc-nd/4.0/). 


\section{Introduction}

This study was part of a bigger comprehensive communitybased HIV stigma reduction and wellness enhancement intervention study in an urban and rural setting in the NorthWest of South Africa, and included people living with HIV (PLWH) and people living close to them (partner, child, close family member, close friend, spiritual leader and community member). The focus in this study was only on people living with HIV and their close family members (CFM). CFM in this study refers to a member who is part of the biological family but excludes the partner or children.

The global AIDS epidemic is one of the greatest challenges in the field of global health, affecting the quality of life of many people and the cost of care. PLWH, those close to them, as well as their healthcare providers are affected by stigma and discrimination, particularly in Southern Africa, where so many are infected and the burden of the disease is significant (Greeff et al., 2010). It has therefore become all the more urgent to find a way to address HIV-related stigma in the South African context (Forsyth, Vandormael, Kershaw, \& Grobbelaar, 2008; Nicolay, 2008).

Although published many years ago, the definition of stigma as conceptualised by Alonzo and Reynolds (1995) is used for this study. According to Alonzo and Reynolds (1995), stigma is "a powerful discrediting and tainting social label that radically changes the way individuals view themselves and are viewed as people" (p. 302). Several conceptual frameworks for understanding HIV stigma and its effects propose that the fear of being identified with HIV prevents people from learning their sero status, changing unsafe behaviours, and caring for PLWH (Wingood et al., 2008).

A number of different frameworks have been published over the years. For instance, Parker and Aggleton (2003) offered a theoretical framework of social inequality as a strategy to understand stigma. The study of Deacon, Stephney, and Prosalendis (2005) focused on social theories of stigma as a problem of fear and blame rather than as a problem of ignorance or a mechanism of social control. Campbell, Foulis, Maimane, and Sibya (2005) proposed a framework regarding the contexts in which stigma occurs: the economic, political, and local community contexts, and the organisational context. The ecological model of human development by Bronfenbrenner (as cited in Asiedu, 2007) stresses the importance of looking at the impacts of HIV and its related stigma on the family members of PLWH. Mak et al. (2007) proposed a social cognitive framework to study the effect of self-stigma on psychological distress. Holzemer et al. (2007) proposed a conceptual model of HIV stigma to understand the stigma process that is specific to HIV in Africa. This model describes HIV-related stigma as a cyclical process within a specific context (the environment, the healthcare system and agents). The stigma process includes four dimensions: triggers of stigma, stigmatising behaviours, types of stigma, and the outcomes of stigma. This model was used as the theoretical framework for the current study.

In the African setting, HIV stigma acts as a powerful barrier to access healthcare as it inhibits HIV testing and disclosure of HIV status (French, Greeff, Watson, \& Doak, 2014). Uys et al.
(2009) found that HIV stigma is a problem for Africa but that it was more intense and more frequent in South Africa. In addition, it posed a serious problem to PLWH and people associated with them as judgement from family members can be one of the worst personal struggles that PLWH have to deal with (Muhomba, 2007). This often leaves the infected individuals with existential questions about the meaning of their infection, their behaviour, as well as their HIV-positive status as it relates to their family relationships. Research by Holzemer et al. (2007) and Ming-Chu et al. (2009) has also shown that as soon as the diagnosis becomes known, spouses, children and family of the infected person also become targets of stigmatisation. The situation thus becomes very difficult if family support is compromised as a result of disclosure. This is of particular concern as Greeff et al. (2008) found that in the African context, PLWH disclose to families first.

Internationally, the literature has shown that HIV stigma tendencies differ in urban and rural settings due to differences in social structure and the experiences of individuals living in those settings. Literature on this theme is however scarce. In their study in five African countries on urban and rural differences on HIV stigma, Naidoo et al. (2007) found that in general, the urban groups described more incidents of stigmatisation and discrimination than the rural groups did. They thus argued that there was a clear difference in character and intensity of stigma between urban and rural groups. However, their findings contradict the results of some other research studies such as the study by Campbell, Nair, Maimane, and Sibiya (2008) which found that there is significant stigmatisation in rural communities due to anonymity and confidentiality being very difficult to maintain in rural areas. Rankin, Brennan, Schell, Laviwa, and Rankin (2005) found that in many African rural communities a restriction on privacy increased the opportunity for stigmatisation because the lives of individuals and families were closely intertwined with those of others. A common thread throughout the literature on urban and rural differences in HIV stigma is that factors such as social structure, economic status and the level of literacy probably determined the manner in which HIV is perceived (French et al., 2014).

Some available literature on HIV stigma reduction programmes or interventions (Bos, Herman, Schaalma, \& Pryor, 2007; Rao et al., 2012) indicates that few effective programmes have been developed and implemented. However, several researchers (Chirwa et al., 2008; Cook, PurdieVaughns, Meyer, \& Busch, 2014; Mahendra et al., 2007; Uys et al., 2009) argue that HIV-related stigma reduction interventions can be effective. In a review by Sengupta, Banks, Jonas, Miles, and Smith (2011), 14 out of 19 interventions demonstrated effectiveness in reducing the stigma of HIV and AIDS. Uys et al. (2009) explored HIV stigma interventions in healthcare settings and found that stigma can be reduced by increasing contact with the affected group, sharing information on HIV stigma and improving coping through empowerment. Further systematic reviews of interventions to reduce HIV-related stigma conducted by Skevington, Sovetkina, and Gillison (2013) and Stangl, Lloyd, Holland, and Baral (2013) found that most interventions were effective at reducing the aspects of stigma, but most did not look at the impact or outcomes. 
In reviewing the literature on HIV stigma-related interventions with PLWH and CFM specifically, little information was found. Krishna, Bhatti, Chandra, and Juvva (2005) aimed to understand the impact of HIV on the family system in an Indian context. Asiedu's (2007) study conducted in Ghana found that many intervention programmes did not consider the stigma family members experienced and the influence it had on their relationships with PLWH. A study conducted in Vietnam by Gaudine, Gien, Thuan, and Dung (2010) concluded that experiences of PLWH, family members, community members and leaders are different for each of these groups. As mentioned above, there are interventions and programmes to reduce HIV stigma, but there is little information with regard to the effectiveness of these programmes.

\section{Research problem statement}

After reviewing the above literature, it became evident that PLWH and CFM all experience stigma, but that CFM also stigmatise PLWH. This severely affects and disturbs the relationship between them which is problematic particularly within the African context, where the CFM plays an important supportive role. The literature did not provide any clear indications whether HIV stigma was higher in urban or in rural communities. Moreover, in the literature review there was also no evidence of HIV stigma reduction interventions that focused only on PLWH and CFM. This gap was identified as a need for an HIV stigma reduction intervention focussing specifically on PLWH and their CFM. The research questions thus focused on whether a community-based HIV stigmareduction intervention could (1) have an influence on stigma experiences of PLWH and CFM, and (2) whether these experiences differ between an urban and a rural setting.

\section{Research aim}

To explore and describe the experiences of PLWH and CFM during and after a community-based HIV stigma reduction intervention through a qualitative interpretive description approach in both an urban and a rural setting in the NorthWest.

\section{Research method and design}

\subsection{Research design}

The study made use of a qualitative description approach (Sandelowski, 2000) to explore and describe the experiences of PLWH and their CFM during and after a community-based HIV stigma reduction intervention.

\subsection{Research method}

\subsubsection{Setting}

The study was conducted in the greater Potchefstroom urban community and in the Ganyesa rural districts of the NorthWest, South Africa. The province is one of the four provinces with the highest HIV prevalence rates in the country. The PLWH in these communities were mainly made up of Setswana-speaking individuals with a black, African sociocultural background. Most come from a lower socioeconomic background, with high unemployment rates and are dependent on family for support.

\subsubsection{Population}

The population consisted of two groups, namely PLWH and CFM from the greater Potchefstroom urban areas and the Ganyesa rural districts in the North-West.

\subsubsection{Sample}

For the PLWH group, purposive voluntary sampling (Burns \& Grove, 2013) was used. PLWH were recruited through mediators with trust relationships with PLWH from local healthcare facilities and non-governmental organisations. The research assistant was informed of willing participants and given their contact information. For PLWH, the inclusion criteria were as follows: Participants had to be older than 25 years and could be male or female, diagnosed with HIV for at least six months, able to communicate freely, be prepared to disclose their HIV status, and willing to be interviewed and recorded. The final sample size was 10 ( 1 male, 9 females) for the urban group, and 8 ( 3 males, 5 females) for the rural group $(n=18)$.

The CFM were identified through snowball sampling (Burns \& Grove, 2013). Each of the attending PLWH was requested to bring one CFM, should they feel comfortable to do so. The following inclusion criteria were used: The CFM had to be part of the extended family, older than 18 years, able to communicate freely and express themselves, and willing to be interviewed and recorded. It excluded partners and children as they were placed in other groups within the bigger intervention. Not all PLWH felt comfortable bringing a CFM and some did not have someone they felt was suitable. Two females were included from the urban group, and five ( 1 male, 4 females) from the rural group $(n=7)$.

\subsubsection{Data collection}

The research project was approved by the School of Nursing Sciences research committee, the Ethics Committee of the North-West University (NWU-00011-09-A1), the provincial Department of Health, as well as the local Department of Health. Written informed consent was obtained through an independent research assistant. The participants were assured that their participation was totally voluntary and that they could withdraw at any stage. Participants were informed of possible feelings of discomfort when sharing their experiences and that support would be available should they need it. The research assistant made appointments with each potential participant and informed them of the arranged date, time and venue. The appointments were conducted in a safe and private venue free of interruptions.

An intervention was conducted with the participants and consisted of an initial two-day workshop with only the PLWH. This workshop focused on understanding HIV stigma, identifying their personal strengths and how to handle disclosure in a responsible manner. This was to prepare them thoroughly on a psychological level for the next phase of the intervention which involved the CFM. The initial workshop was followed by 
a three-day community-based HIV stigma reduction intervention presented to PLWH and CFM together in both the urban and rural settings. The underlying aim of the intervention was to increase knowledge about HIV stigma and coping, to equalise the relationship between PLWH and CFM, and to empower both groups to become leaders in reducing the stigma attached to HIV in their communities. Two facilitators, a non-infected person and an infected person, were trained to present the workshop. The workshop consisted of focused presentations, followed by activity-based group discussions. The focus on the first day was on understanding HIV stigma and coping with it and giving PLWH and CFM an opportunity to share their experiences. The second day focused on bridging the knowledge and understanding they had gained the previous day, training them in project planning and using this knowledge constructively in planning their own HIV stigma reduction project with other CFM in the community. The project was executed over a one-month period with the researchers forming a supportive network and monitoring their progress. This was followed up by a third day during which the participants reported back on their community project and were evaluated by relevant community stakeholders and the researchers on the success of their project.

Data collection took place after the intervention by means of in-depth interviews with both PLWH and CFM. Participants were informed that the researcher would make use of digital tape recordings and that the researcher was an experienced interviewer. They were thoroughly prepared for the interviews and allowed time for queries prior to starting. Openended questions were formulated for the in-depth interviews, reviewed beforehand with experts in the field, and evaluated for their suitability with two participants. The following question was asked to PLWH during the in-depth interviews: How did you experience the workshop and project with CFM and others in the group? The CFM were asked: How did you experience the workshop and project with the PLWH and others in the group? Communication techniques such as paraphrasing, summarising, reflection, minimal verbal response and probing were used (Okun, 1992). The interviews took 60-90 min to complete. Field notes were taken after each interview, focussing on methodological, theoretical and personal notes.

\subsubsection{Data analysis}

Digital voice-recorded interviews were accurately transcribed to be used for data analysis. The open coding process of Tesch (as cited in Creswell, 2014) was followed. The researcher got a sense of the whole by reading the full text, then developed codes, coded the text, and turned them into subcategories, categories and themes by moving from descriptive to interpretative analysis. An independent co-coder was used to also analyse the data. Consensus conversations took place about the analysed data. After analysis both coders agreed that there were no real differences in the findings between the urban and the rural groups and the data was thus pooled.

\section{Ethical considerations}

The researcher had access to the community through previous studies, as well as through non-governmental organisations (NGOs). Due to the highly sensitive nature of the study, great care was taken with the inclusion of the PLWH. They were always approached through intermediaries to ensure that they were not compromised when choosing to participate in the study. Due to the nature of the intervention, a workshop prior to their contact with others was given to them to empower them with responsible disclosure management. Ethical aspects were observed throughout the study (Burns \& Grove, 2013). A risk-benefit ratio analysis was conducted and led to the two-day initial workshop with the PLWH. Their travel expenses were covered if they preferred to travel to another venue and they were served light refreshments. Participants were informed that their recorded interviews would be kept confidential, anonymous and private throughout the process. The participants were each given a code and the data stored in a safe place. Hard copies were locked away and the electronic data protected by a password. The data will be kept for five years.

\section{Trustworthiness}

To ensure trustworthiness in this study, the researcher applied Lincoln and Guba's model (as cited in Botma, Greeff, Mulaudzi, \& Wright, 2010). Truth value was ensured through prolonged engagement with the participants during the intervention, the project and during the in-depth interviews. Reflectivity was achieved by writing field notes during and after the intervention and the interviews, and having discussions with the study leaders. The use of transdisciplinary researchers ensured investigator triangulation. Regular discussions with study leaders improved credibility. Welldesigned sampling and a dense description of the research methodology and data made applicability possible. Consistency was ensured by maintaining an audit trail and by using an independent co-coder during data analysis. A dense description of the study and data made replication possible. An audit trail, investigator triangulation and reflexivity ensured neutrality.

\section{Findings and discussion}

Findings from the in-depth interviews identified four main themes for PLWH, and five main themes for CFM (summarised in Table 1). Where smaller differences were noted between the urban and the rural groups, they are mentioned. The findings are enriched by quotes, and reference is made to applicable literature.

\subsection{Findings for PLWH}

7.1.1. Theme one: initial fear to attend the workshop changed to support in the group

The PLWH verbalised feelings of loneliness and were initially scared to attend the workshop: "I was so scared...felt lonely." There was a strong realisation that non-disclosure could lead to isolation and stress: "... stress will catch up with you and you get sick..." Disclosure is usually stressful and many people prefer to keep their HIV-status a secret or avoid seeking 
Table 1 - Summary of findings.

Themes

Subthemes

Findings for the PLWH

Initial fear to attend the workshop changed

to support in the group

Knowledge gained about HIV stigma and

how to cope with it

Became aware of the painful experiences of HIV stigma

Being part of the project was meaningful yet difficult

Findings for the CFM

Initial reluctance to join the group turned meaningful

The workshop changed the attitudes of CFM

Awareness of the painful experiences of HIV stigma created by healthcare services

The knowledge gained empowered CFM as leaders

Conducting the project was meaningful yet difficult
Experienced loneliness

Initial fear to attend the workshop

Non-disclosure lea to isolation

Workshop a safe environment to disclose

Leaving the safe environment to return home was stressful

Experienced pride and happiness to be part of the group

Gained a positive self-image

A message of hope and a meaningful life

Did not know the word "stigma"

Realised stigma happened in different contexts and ways

Stigma is discriminating

Helped to understand and cope with stigma

Experienced the workshop as positive

Experiences of stigmatisation, trauma and neglect

Gained hope, acceptance and understanding

Proud to be part of the group

Participating in the project gave them hope and strength

Excited to see change in the community

Some community members came forward to join them

Nervous to join the group

Realisation of own stigmatising behaviour

Experienced the workshop and project positively

Realised hurt of PLWH prevents disclosure

Experienced a change in attitude

The workshop and project taught them to respect and love PLWH

Realisation of stigmatisation due to practices in healthcare services

Healthcare workers fail to maintain confidentiality and privacy

Counsellors not to be trusted

Fear that testing will bring disclosure

Not familiar with the word "stigma"

Knowledge empowered them

Lack of knowledge leads to stigmatisation

Empowered as leaders to talk to the community about stigma

Saw a positive response after the project

Rural group experienced negative responses due to denial and resistance

to talk publicly about stigma

Psycho-drama changed the response to positive

Disappointment if attendance was poor healthcare due to fear of being stigmatised (Derlega, Winstead, Greene, Serovich, \& Elwood, 2006). According to Holzemer et al. (2007), social exclusion, rejection, and high stress due to stigma and economic pressures may lead to stress-related mental illness.

The participants experienced the workshop as a safe and supportive environment for disclosure, without discrimination, rejection and value judgements: "We didn't judge each other, and there was openness...it felt like a blanket that keeps you warm...sharing the same problem..." Leaving this safe environment to go back home was experienced as stressful: "I felt there was no pain, and if I go home I feel the pain again." However, they also felt that the initial feelings of fear changed to pride and happiness to be part of the group: “...made me feel comfortable and strong." According to Cook et al. (2014), interventions can promote a sense of belonging and may be an effective strategy for reducing stigma.

The workshop encouraged a positive self-image among the PLWH: "...it helped me to accept myself and understand myself better." Uys et al. (2009) confirmed this in their study, stating that PLWH involved in their intervention reported an increased self-esteem. The PLWH received a message of hope that made them feel strong and they realised that they could still have a long and meaningful live: “...got hope in that sense you feel you accepted yourself and you can live long with this disease." Greeff et al. (2008) too found that interaction in a group with other infected people or when other infected people disclosed their status helped PLWH to have more courage to disclose their status than when alone in this situation. In fact, stigma can have such a deleterious effect on the stigmatised person that Yang and Kleinman (2008) refer to social death instead of stigma as stigma can turn a person into a nonperson.

\subsubsection{Theme two: knowledge gained about HIV stigma and} how to cope with it

The PLWH indicated that they were not familiar with the word "stigma": "It was my first time I hear the word stigma... I knew nothing about it." During the workshop, "They explained what HIV was and I got to understand... I was stigmatised," and "Before 
the workshop people in families were dying because they did not know what HIV and AIDS were." Uys et al. (2009) found that their intervention increased the understanding and knowledge of HIV stigma and discrimination.

This was a learning experience for the PLWH as they realised that stigma happens in different contexts: “...at the clinic, hospital and the community..." They realised it is discriminating: "Stigma is a powerful weapon... a social weapon to hurt others..." and that stigma comes in different forms: "...a sign, gossiping or labelling other persons." Moreover, according to Holzemer et al. (2007), AIDS-related discrimination may occur at various levels, in both family and community settings, as well as in institutional settings.

The PLWH experienced the workshop as positive because it helped them to understand and cope with stigma, and carry this over to others: "...feel that what I learned here, give us power to share with other people in the community." According to Greeff et al. (2008), their study showed that knowledge of HIV made the PLWH feel more worthwhile because disclosure had some meaning. They concluded that if stigma reduction interventions were successful, life satisfaction would be aided (Greeff et al., 2010).

7.1.3. Theme three: became aware of the painful experiences of HIV stigma

The PLWH verbalised their experiences of stigmatisation, trauma and neglect by their families: “...my family doesn't accept me because I'm HIV positive... I was very ill and my family didn't take care of me...my sister used to beat me..." Sharing stigma experiences during the interventions confirmed findings in the literature of severe stigmatisation, trauma and neglect by family (Greeff \& Phetlhu, 2007; Holzemer et al., 2007) especially in the African culture where PLWH are at a great risk of experiencing abuse within the family setting and specifically in the extended family (Dlamini et al., 2007).

The workshop, however, gave them hope, self-acceptance and understanding: "It has helped me to accept myself and understand myself better...after the workshop I feel so strong and happy and I learnt how to know myself and how to cope with it." The participants (PLWH) regained hope for their future and valued their families more and had a positive attitude towards life in general. According to Mohanan and Kamath (2009), family support has a positive impact on PLWH and also benefits family relationships. Pinel and Bosson (2013) found that there can be relief for the stigma-targeted individual by placing less focus on the stigmatised status and more focus on personal values and goals.

7.1.4. Theme four: being part of the project was meaningful yet difficult

The participants (PLWH) experienced pride because of being part of the group: “... felt proud to be part of the project...I felt so proud." They expressed hope and strength while doing the project: "I have hope... I was able to teach people and I gained strength to disclose in front of people." A study by Rao et al. (2012) indicated similar findings in the sense that an intervention focused on participants socially supporting one another can lead to PLWH being able to better cope with HIV stigma. They participants were also excited to see change happening in their community: "...change in the way people see those with
HIV, as well as change in people accepting themselves as HIV positive". However, during the project, the rural group found that people still stigmatised them, but that people from the community came forward to join them in the project: "Here in our village there's a lot of stigma..." and "... another one didn't want to hear about HIV...but after this project they have become less... people are willing to join us on our project." Wong et al. (2009) mention the positive effects of empowerment for those who disclose their HIV status and overcome feelings of powerlessness and can then engage in positive, lifeaffirming activities.

\subsection{Findings for the CFM}

\subsubsection{Theme one: initial reluctance to join the group turned} meaningful

The participants of the CFM group indicated that they were initially nervous to join the group: "I was very nervous and I didn't understand why I as a person without HIV had to be grouped together with people who were." However, they came to realise that they were stigmatising PLWH: "It was painful to realise that I was stigmatising... and what stigmatising did to other people... I have hurt people with my words." According to Campbell et al. (2005), stigmatisation by one's family members, at the very time one most needs their support, is often cited as the most hurtful and damaging form of stigma. In general the participants in this group found that participating in the workshop and project was a positive experience: "I have confidence of standing in front of people teaching. We got information from the workshop and deliver it to the community..." According to Greeff et al. (2008), the disclosure of one's HIV status can form part of a comprehensive stigma reduction process in communities and can bring about broader social change, resulting in enabling environments.

\subsubsection{Theme two: the workshop changed the attitudes of CFM}

The workshop helped CFM to understand that PLWH are afraid to disclose their status because of the pain it can cause. The workshop opened their eyes and changed their attitude towards PLWH: "I am no longer going to stigmatise people...in the past I did not have the knowledge, but now I have it," and "The workshop and the project made a difference in my life...I learned that I must respect and love people who have been infected with this disease." The findings of Gilbert and Walker (2010) confirm that fear of stigmatisation and rejection is a main reason why PLWH do not want to disclose their status, especially to family members.

7.2.3. Theme three: awareness of the painful experiences of HIV stigma created by healthcare services

This was an experience mentioned only by the CFM in the rural group. The CFM became aware of the HIV stigma caused by healthcare services. They mentioned how PLWH are stigmatised whereby their files in the clinics are a different colour: "Their files are separate, the colour is not the same as others..." The colour-coded files lead to gossiping and discrimination, resulting in PLWH often refusing to go to the clinics: "People refuse to go get treatment because of this discrimination...look at her she is here for her treatment she has a black file." This experience confirms the finding of Muhomba 
(2007) who found that stigma stimulates people to act in ways that directly harm others leading to discrimination and isolation of the patients.

Failure to maintain confidentiality and privacy by healthcare workers was an issue because this made people afraid to go to the clinics for testing: "In the government department you cannot see anyone there but the community people and I'm not 100 per cent sure about the privacy at the hospital there...". This finding is supported by Holzemer et al. (2007) who also found that the participants in their study reported healthcare workers as a source of stigmatisation. CFM also mentioned that the counsellors could not be trusted: "People giving counselling talk behind our backs." People are thus afraid to test: "... because they know that as soon as they get tested someone will be talking about them". Bell, Mthembu, O'Sullivan, and Moody (2007) and Greeff et al. (2008) also found that stigma and discrimination by healthcare providers are still widespread and can be life-threatening for PLWH.

\subsubsection{Theme four: the knowledge gained empowered CFM as} leaders

Just like the PLWH, the CFM also indicated that they were not familiar with the word "stigma": "I didn't know about this stigma before..." The workshop helped CFM to understand what stigma is and they felt good and empowered by the knowledge they received. The group reflected on what they had learned and discussed the fact that a lack of information actually leads people to stigmatise others: "You must have knowledge...if you have full information you can't do the wrong thing." Thus, a combination of counselling, education and contact is very important to reduce HIV stigma (Mahendra et al., 2007). As CFM, they felt empowered as leaders to talk to the community about stigma: "It made me feel good because I was a leader in the group and people were listening to me."

7.2.5. Theme five: conducting the project was meaningful yet difficult

Both the urban and rural CFM groups were involved in psychodrama as part of their project with other family members. CFM experienced a change in the way people saw HIV and stigma as they could identify with the drama "...said that they were living with people with HIV at home ... we are bringing change in the way people see those with HIV, as well as change in people accepting themselves ... people are willing to join us on our project." Machtinger et al. (2015) studied a workshop-based intervention leading to public theatre performances about living with HIV attended by both PLWH and others. Through this intervention participants realised that their stories could impact other people and they could become a voice advocating a change in social norms. The current study made a similar observation.

However, the rural group found that invitations to the psycho-drama were negatively received: "Some of them haven't accepted that HIV can be talked about publicly. People don't like it when we speak about HIV and take it as an insult to talk about it." However, people were more willing to attend their show if food and drinks were provided: "People don't like it when we speak about HIV, it's better to provide something to eat." Once they got people to attend the psycho-drama, they got a positive reception from the audience. According to Tshabalala (2009), in some African communities people are more fearful of the social consequences of AIDS than of the disease itself. The urban group experienced disappointment that not all people turned up as promised: “... say yes to me ... they didn't come."

\section{Conclusion}

No noteworthy differences were noted between the expressed experiences of PLWH and CFM living in rural and those living in urban areas after they had undergone the HIV stigma reduction intervention. This outcome could be due to the fact that both urban and rural groups were mostly Setswanaspeaking and that the cultural contexts were the same. The way in which the intervention was planned and implemented was successful and can thus be repeated.

The shared experiences of PLWH and CFM indicated that the intervention achieved the set goals of increasing knowledge about HIV stigma and coping with it, and enhancing the relationships between PLWH and their CFM through the equalised way in which they were included in the intervention. The PLWH involved in the intervention felt a strong sense of being accepted and respected. They felt more supported by CFM, and in turn the CFM became aware of their stigmatising behaviour and showed more compassion towards PLWH during and after the intervention. The HIV stigma reduction project in which the two groups were involved together with other CFM in their community empowered them to become leaders in HIV stigma reduction in their own community. The group experience empowered them to successfully plan a project and gave them the confidence to share it with the community. Pride became evident as they succeeded. They learnt to trust and support each other and that together they had a better chance of silencing the voice of HIV stigma. Participants gained confidence and their initial experience of fear diminished with the support and trust they gained from the group and their feelings changed to hope, acceptance and trust.

\section{Limitations of the study}

A possible limitation of the study is that the sample size for CFM could have been bigger; however, not all of the PLWH had a CFM or felt comfortable about inviting a CFM to attend the intervention. The initial group of PLWH was selected as part of the bigger study and no other PLWH could be introduced to the study at this stage of the research.

\section{Recommendations}

More community-based HIV stigma reduction projects with PLWH and CFM, as well as other groups should be rolled out to promote a better understanding of HIV stigma and how to cope with it. Such a project also sends a strong message that the community has a role to play in this process. Nurses in clinics working with PLWH should be trained to handle stigma reduction programmes through in-service education. Moreover, HIV stigma reduction should be included in educational programmes offered at primary health clinics to PLWH and 
CFM, as well as other groups. Both PLWH and their CFM could be invited to participate in support groups to reduce HIVrelated stigma. The inclusion of HIV stigma reduction interventions in the curricula of all health professionals could also prove to be useful. These suggestions can help to ensure the sustainability of HIV stigma reduction programmes in the community.

The results of the current study have important implications for further research in HIV-related stigma reduction interventions with PLWH and CFM, as well as other groups in other provinces in South Africa and other countries. The study has the potential to be used for long-term monitoring studies of HIV stigma reduction interventions. The intervention can be used in an HIV stigma reduction study focussing on the community and can be rolled out to primary healthcare settings.

\section{Acknowledgements}

1. SANPAD for the financial support received to conduct the research as well as to the Faculty of Health Sciences for the student bursary.

2. Ms Poncho Molaudzi for her help as fieldworker and her warm and loving way of sharing experiences.

3. Participants in the study who gave their permission to be part of the research and for their support and contributions.

\section{R E F E R E N C E S}

Alonzo, A. A., \& Reynolds, N. R. (1995). Stigma, HIV and AIDS: an exploration and elaboration of a stigma trajectory. Social Science and Medicine, 41(3), 303-315.

Asiedu, G. B. (2007). Challenging HIV-related stigma and discrimination: The role of the family life educator. Manhattan, KS: Kansas State University.

Bell, E., Mthembu, P., O'Sullivan, S., \& Moody, K. (2007). Sexual and reproductive health services and HIV testing: perspectives and experiences of women and men living with HIV and AIDS. Reproductive Health Matters, 15(29), 113-135. http://dx.doi.org/ 10.1016/S0968-8080(07)29029-9.

Bos, A. E. R., Herman, P., Schaalma, H. P., \& Pryor, J. B. (2007). Reducing AIDS-related stigma in developing countries: the importance of theory- and evidence-based interventions. Psychology, Health \& Medicine, 13(4), 450-460.

Botma, Y., Greeff, M., Mulaudzi, M., \& Wright, S. (2010). Research in health sciences. Cape Town: Heinemann.

Burns, N., \& Grove, S. K. (2013). The practice of nursing research: Appraisal, synthesis and generation of evidence (7th ed.). St. Louis, MI: Elsevier Saunders.

Campbell, C., Foulis, C. A., Maimane, S., \& Sibya, Z. (2005). "I have an evil child at my house": stigma and HIV/AIDS management in a South African community. American Journal of Public Health, 95(5), 808-815.

Campbell, C., Nair, Y., Maimane, S., \& Sibiya, Z. (2008). Supporting people with AIDS and their careers in rural South Africa: possibilities and challenges. Health and Place, 14(3), 507-518.

Chirwa, M. L., Greeff, M., Kohi, T. W., Naidoo, J. R., Makoae, L. N., Dlamini, P. S., et al. (2008). HIV stigma and nurse job satisfaction in five African countries. Journal of the Association of Nurses in AIDS Care, 20(1), 14-21. http://dx.doi.org/10.1016/ j.jana.2008.10.001.
Cook, J., Purdie-Vaughns, V., Meyer, I., \& Busch, J. (2014). Intervening within and across levels: a multilevel approach to stigma and public health. Social Science \& Medicine, 103, 101-109. http://dx.doi.org/10.1016/j.socscimed.2013.09.023.

Creswell, J. W. (2014). Research design: Qualitative, quantitative, and mixed methods approaches (4th ed.). Thousand Oaks, CA: Sage.

Deacon, J., Stephney, I., \& Prosalendis, S. (2005). Understanding HIV/AIDS stigma: A theoretical and methodological analysis. Cape Town: Human Sciences Research Council.

Derlega, V. J., Winstead, B. A., Greene, K., Serovich, J., \& Elwood, W. N. (2006). Reasons for HIV disclosure/ nondisclosure in close relationships: testing a model of HIV disclosure decision making. Journal of Social and Clinical Psychology, 23(6), 747-767. http://dx.doi.org/10.1521/ jscp.23.6.747.54804.

Dlamini, P. S., Kohi, T. W., Uys, L. R., Phetlhu, R. D., Chirwa, M. L., Naidoo, J. R., et al. (2007). Verbal and physical abuse and neglect as manifestations of HIV/AIDS stigma in five African countries. Public Health Nursing, 24(5), 389-399.

Forsyth, B., Vandormael, A., Kershaw, T., \& Grobbelaar, J. (2008). The political context of AIDS-related stigma and knowledge in a South African township. Community Journal of Social Aspects of HIV/AIDS, 5(2), 74-83.

French, H., Greeff, M., Watson, M. J., \& Doak, C. M. (2014). A comprehensive HIV stigma-reduction and wellnessenhancement community intervention: a case study. The Journal of the Association of Nurses in AIDS Care, 26(1), 81-96. http://dx.doi.org/10.1016/j.jana.2014.03.007.

Gaudine, A., Gien, L., Thuan, T. T., \& Dung, D. V. (2010). Perspectives of HIV-related stigma in a community in Vietnam: a qualitative study. International Journal of Nursing Studies, 47(1), 38-48. http://dx.doi.org/10.1016/ j.ijnurstu.2009.06.004.

Gilbert, L., \& Walker, L. (2010). 'My biggest fear was that people would reject me once they knew my status...': stigma as experienced by patients in an HIV/AIDS clinic in Johannesburg, South Africa. Health and Social Care in the Community, 18(2), 139-146. http://dx.doi.org/10.1111/j.13652524.2009.00881.x.

Greeff, M., \& Phetlhu, R. (2007). The meaning and effect of HIV/ AIDS stigma for people living with AIDS and nurses involved in their care in the North West Province, South Africa. Curationis, 30(2), 12-23.

Greeff, M., Phetlhu, D. R., Makoae, L. N., Dlamini, P. S., Holzemer, W. L., Naidoo, J. R., et al. (2008). Disclosure of HIV status: experiences and perceptions of persons living with HIV/AIDS and nurses involved in their care in Africa. Qualitative Health Research, 18(3), 311-324.

Greeff, M., Uys, L. R., Wantland, D., Makoae, L., Chirwa, M., Dlamini, P., et al. (2010). Perceived HIV stigma and life satisfaction among persons living with HIV infection in five African countries: a longitudinal study. International Journal of Nursing Studies, 47, 475-486. http://dx.doi.org/10.1016/ j.ijnurstu.2009.09.008.

Holzemer, W. L., Uys, L. R., Makoae, L., Stewart, A., Phetlhu, R., Dlamini, P., et al. (2007). A conceptual model of HIV/AIDS stigma from five African countries. Journal of Advanced Nursing, 58(6), 541-551. http://dx.doi.org/10.1111/j.13652648.2007.04244.x.

Krishna, V. A. S., Bhatti, R. S., Chandra, P. S., \& Juvva, S. (2005). Unheard voices: experiences of families living with HIV/AIDS in India. Contemporary Family Therapy, 27(4), 483-489. http:// dx.doi.org/10.1007/s10591-005-8235-9.

Machtinger, E. L., Lavin, S. M., Hilliard, S., Jones, R., Haberer, J. E., Capito, K., et al. (2015). An expressive therapy group disclosure intervention for women living with HIV improves social support, self-efficacy, and the safety and quality of relationships: a qualitative analysis. Journal of the Association of 
Nurses in AIDS Care, 26(2), 187-198. http://dx.doi.org/10.1016/ j.jana.2014.05.001.

Mahendra, V. S., Gilborn, L., Bharat, S., Mudoi, R., Gupta, I., George, B., et al. (2007). Understanding and measuring AIDSrelated stigma in health care settings: a developing country perspective. Journal of Social Aspects of HIV/AIDS Research Alliance, 4(2), 616-625.

Mak, W. W. S., Cheung, R. Y. M., Law, R. W., Woo, J., Li, P. C. K., \& Chung, R. W. Y. (2007). Examining attribution model of selfstigma on social support and psychological well-being among people with HIV/AIDS. Journal of Social Science \& Medicine, 64, 1549-1559.

Ming-Chu, F., Jui-Ying, F., Tun-Chieh, C., Po-Liang, L., NaiYing, K., \& Yen-Hsu, C. (2009). Stress, needs, and quality of life of family members caring for adults living with HIV/AIDS in Taiwan. Aids Care, 21(5), 482-489.

Mohanan, P., \& Kamath, A. (2009). Family support for reducing morbidity and mortality in people with HIV/AIDS. New York, NY: Wiley.

Muhomba, M. (2007). The relationship between HIV/AIDS-related stigma and the process of forgiveness with a special focus on the family context. Lexington, KY: University of Kentucky.

Naidoo, J. R., Uys, L. R., Greeff, M., Holzemer, W. L., Makoae, L., Dlamini, P., et al. (2007). Urban and rural differences in HIV/ AIDS stigma in five African countries. African Journal of AIDS Research, 6(1), 17-23.

Nicolay, N. (2008). Summary of provincial HIV and AIDS statistics for South Africa. Retrieved from http://www.callawayleadership. com/downloads/CLI_LE_episode18_summary_HIV_stats_SA. pdf.

Okun, B. F. (1992). Effective helping: Interviewing and counseling techniques. Pacific Grove, CA: Brooks/Cole.

Parker, R., \& Aggleton, P. (2003). HIV and AIDS-related stigma and discrimination: a conceptual framework and implications for action. Journal of Social Science \& Medicine, 57, 13-24.

Pinel, E. C., \& Bosson, J. K. (2013). Turning our attention to stigma: an objective self-awareness analysis of stigma and its consequences. Basic and Applied Social Psychology, 35, 55-63. http://dx.doi.org/10.1080/01973533.2012.746593.

Rankin, W. W., Brennan, S., Schell, E., Laviwa, J., \& Rankin, S. H. (2005). The stigma of being HIV-positive in Africa. Plos Medicine, 2(8), 702-704.

Rao, D., Desmond, M., Andrasik, M., Rasberry, T., Lambert, N., Cohn, S. E., et al. (2012). Feasibility, acceptability, and preliminary efficacy of the unity workshop: an internalized stigma reduction intervention for African American women living with HIV. AIDS Patient Care and STDs, 26(10), 614-620. http://dx.doi.org/10.1089/apc.2012.0106.

Sandelowski, M. (2000). Focus on research methods: whatever happened to qualitative description? Research in Nursing \& Health, 23(4), 334-340.

Sengupta, S., Banks, B., Jonas, D., Miles, M. S., \& Smith, G. C. (2011). HIV intervention to reduce HV/AIDS stigma: a systematic review. AIDS Behavior, 15, 1075-1087.

Skevington, S. M., Sovetkina, E. C., \& Gillison, F. B. (2013). A systemic review to quantitatively evaluate 'Stepping Stone': a participatory community-based HIV/AIDS prevention intervention. AIDS and Behavior, 17(3), 1025-1039. http:// dx.doi.org/10.1007/s10461-012-0327-6.

Stangl, A., Lloyd, J., Holland, C., \& Baral, S. (2013). A systematic review of interventions to reduce HIV-related stigma and discrimination from 2002 to 2013: how far have we come? Journal of International AIDS Society, 16(3), 18734. http:// dx.doi.org/10.7448/ias.16.3.18734.

Tshabalala, J. (2009). A model of cognitive behavioural therapy for HIV positive women to assist them in dealing with stigma (Doctoral thesis). Retrieved from: http://upetd.up.ac.za/thesis/available/ etd-10172009-130134/.

Uys, L. R., Chirwa, M., Kohi, T., Greeff, M., Naidoo, J., Makoae, L., et al. (2009). Evaluation of a health setting-based stigma intervention in five African countries. AIDS Patient Care and STDs, 23(12), 1059-1066. http://dx.doi.org/10.1089/ apc. 2009.008.

Wingood, G. M., Reddy, P., Peterson, S. H., Diclemente, R. J., Nogoduka, C., Braxton, N., et al. (2008). HIV stigma and mental health status among women living with HIV in the Western Cape, South Africa. South African Journal of Science, 104, 237-240.

Wong, L. H., Van Rooyen, H., Modiba, P., Richter, L., Gray, G., Mcintyre, J. A., et al. (2009). Test and tell: correlates and consequences of testing and disclosure of HIV status in South Africa. Journal of Acquired Immunodeficiency Syndrome, 50(2), 215-222. http://dx.doi.org/10.1097/ QAI.0b013e3181900172.

Yang, L. H., \& Kleinman, A. (2008). 'Face' and the embodiment of stigma in China: the case of schizophrenia and AIDS. Social Science and Medicine, 67(3), 398-408. http://dx.doi.org/10.1016/ j.socscimed.2008.03.011. 